\title{
The Woman Who Collected Solved Crossword Puzzles
}

There is little market value for these two collections: I collect the names of stories that I will never write; Anna collects solved crossword puzzles. That said, you have to admit that there are things to learn from this kind of puzzle. Such as, the galaxy nearest to the Milky Way, nine letters? Andromeda. And the planet closest to earth, four letters? Mars. The capital of Norway, nine letters? Jerusalem. Crossword puzzles that have fallen victim to typos she keeps in a separate file. As she does with puzzles that were, for whatever reason, not completely solved: clues too difficult, time ran out. She already has more than seven hundred items in her collection, in various languages: Russian, French, Arabic, Italian, English, and more. One of the puzzles, so Anna says, is from a language whose origins are unknown-Basque. One puzzle especially dear to her is a puzzle that was solved by her grandmother in 1931; it was cut out of a Yiddish newspaper, Da Spiel, published in Riga, the capital of Latvia.

And more: One of Columbus's ships, five letters? Pinta. Half of half, seven letters? Quarter. The reason for the death of Romeo and Juliet, four letters? Love. Abroad, Anna's friends are always searching for crossword puzzles for her in newspapers and magazines left on trains. One day I must try to write a story about Anna; I will begin in St. Petersburg, the city of her birth, where at the end of the seventies, she studied chemistry. These days she sells cosmetics for a large chain. In her childhood, she stuttered. In 1991, after she learned Hebrew, this flaw disappeared. 